\title{
Study on magnetic loss properties of ultra-thin nanocrystalline soft magnetic alloy $\mathrm{Fe}_{73.4} \mathrm{Cu}_{0.6} \mathrm{Nb}_{3.5} \mathrm{Si}_{13.5} \mathrm{~B}_{9.0}$ \\ KunMing Qian ${ }^{1, a^{*}}$, Jie Hao ${ }^{1, b}$, Song $\mathrm{Ji}^{1}$, YanSong Zhang ${ }^{1}$, Ang Ding ${ }^{1}$, Ming Li $\mathrm{Li}^{1}$, JingHui Huang ${ }^{1}$ \\ ${ }^{1}$ Inner Mongolia Metallic Materials Research Institute,199 Lingyun Road, Ningbo, 315103, China \\ aqiankm@126.com, bhao_jie82@163.com
}

Keywords: Nanocrystalline, Soft magnetic alloys, Magnetic loss, Ultra-thin.

\begin{abstract}
The magnetic loss characteristics of ultra-thin nanocrystalline magnetic alloy $\mathrm{Fe}_{73.4} \mathrm{Cu}_{0.6} \mathrm{Nb}_{3.5} \mathrm{Si}_{13.5} \mathrm{~B}_{9.0}$ with $14 \mu \mathrm{m}$ were studied, and compared with conventional nanocrystalline magnetic alloy strip with the thickness of the $26 \mu \mathrm{m}$. It was found that reducing the thickness of alloy strip could significantly reduce the magnetic loss $(\mathrm{P})$ of the alloys. The frequency magnetic loss $\left(\mathrm{P}_{\mathrm{f}}\right)$ of nanocrystalline soft magnetic alloy has shown a typical fractal structure, namely, $\mathrm{P}_{\mathrm{f}}=\mathrm{P}_{\mathrm{O}} \mathrm{P}^{\mathrm{Df}}$. The strip thickness had a significant impact on the variation of the fractal dimension $\mathrm{D}_{\mathrm{f}}$, the parameter Po, and its work magnetic induction $\mathrm{B}_{\mathrm{m}}$.
\end{abstract}

\section{Introduction}

Soft magnetic material as key functional materials, which are widely used in electronics, electricity, communications, automatic control, computer and defense fields, and so on, are indispensable to modern engineering, and played major functions for the transfer, processess and storage of energy and information [1-5]. With the development of engineering technology, a higher performance requirement for the soft magnetic material is necessary. The higher performance requirements imply that the soft magnetic material must possess a high saturation magnetic flux density, high magnetic permeability and low loss in performance, namely the high overall soft magnetic properties. The Japanese scholars Yoshizawa, who firstly and successful excogitate the nanocrystalline soft magnetic materials with the virtue of nano duplex structure. The nano duplex structures which are composed of nanocrystals and ferromagnetic amorphous phase in its internal structure, which could induced the ferromagnetic AC coupling. In the history of the development of a soft magnetic material, it is the first time to set the traditional performance advantages of soft magnetic material into one material, and integrated very excellent soft magnetic properties [6]. The new materials are used in the workplace, and replaced the traditional soft magnetic materials, in which the traditional soft magnetic materials can not be in it, and show great advantages and had a broad application prospects.

Magnetic loss is an important performance indicator for soft magnetic material. Under the background of the rapid development, the trend of electronic power apparatus is toward to miniaturization of small, high-frequency direction, and the magnetic loss index have become a key factor in achieving the compact high frequency. There exist two technical means to reduce the magnetic loss for soft magnetic. Firstly, it is to develop the new low-loss magnetic materials, such as nanocrystalline soft magnetic materials. Another important technical approach is to reduce the thickness of the soft magnetic alloy ribbon in order to reduce eddy current losses, which can reduce the magnetic loss remarkably, especially for the apparatus working at high frequencies, such as nanocrystalline soft magnetic materials, amorphous soft magnetic materials, nanocrystalline soft magnetic alloy film. These soft magnetic materials are currently being studied by many researchers, are a typical example of new low-loss magnetic materials, which can be used with the aim to further improve the use of the frequency. At present, the Fe-based nanocrystalline soft magnetic alloy, can be prepared with the thick of strip below $20 \mu \mathrm{m}$ in Japan, but in China manufacturers only can produced the thick of strip above $25 \mu \mathrm{m}[7,8]$. If we can further reduce the strip thickness of nanocrystalline soft 
magnetic alloy and reduce the losses, it can be used at higher frequencies, to extend the class of new materials applications, and exhibit undoubtedly significant.

In this paper, the nanocrystalline soft magnetic alloy thin ribbon, its magnetic loss characteristics and magnetic loss mechanism are studied, and compare with the conventional alloy thin strip through comparing the thick discuss.

\section{Experiments}

Cast ingots of soft magnetic alloy with nominal composition (in at. \%) Fe 73.5, Cu1, Nb3, Si13.5, B9, were obtained by arc melting the metals $\mathrm{Fe}, \mathrm{Cu}, \mathrm{Nb}, \mathrm{Si}, \mathrm{Fe}-\mathrm{B}$ alloy ( $\mathrm{Fe}, \mathrm{Cu}, \mathrm{Nb}, \mathrm{Si}, \mathrm{Fe}-\mathrm{B} 99.9 \%$, Fe 99.8 pure) under high purity Ar atmosphere. Then the ultra-thin amorphous ribbons about $20 \mathrm{~mm}$ wide, 14 and $26 \mu \mathrm{m}$ thick were prepared by single-roller melt spinning method. Afterwards these ultra-thin ribbons were wound into toroidal core samples of $10 \mathrm{~mm}$ inner diameter and $18 \mathrm{~mm}$ outer diameter. To obtain the characteristic nanocrystalline structure, these toroidal samples were submitted to isothermal annealing at temperatures of $580{ }^{\circ} \mathrm{C}$ for $40 \mathrm{~min}$ under the protection of hydrogen atmosphere. Then the magnetic losses of the sample were measured under the frequency range of $100 \mathrm{KHZ} \sim 600 \mathrm{KHZ}$ with the $\mathrm{B}-\mathrm{H}$ instrument.

\section{Results and Discussions}

Magnetic Loss. The magnetic losses of the samples were measured at the frequency range of $100 \mathrm{~K}$ $\mathrm{H}_{\mathrm{Z}} \sim 600 \mathrm{KH}_{\mathrm{Z}}$ with the $\mathrm{B}-\mathrm{H}$ instrument under the working magnetic induction value $\mathrm{Bm}$ of $0.1 \sim$ 0.04T, and the magnetic loss $\mathrm{P}$ (f) values were listed in Table 1. The thickness of thin ribbon had a remarkable effect on the magnetic loss. From Table 1, it could be found that the magnetic losses of the ribbons with the thickness of $14 \mu \mathrm{m}$ were reduced by $30 \%$ compared with that of the ribbons with the thickness of $26 \mu \mathrm{m}$. With increase of the frequency, the reductions of the magnetic losses become smooth slightly compared the $14 \mu \mathrm{m}$ ribbons with the $26 \mu \mathrm{m}$ ribbons. The results indicated that reducing the strip thickness to reduce the magnetic loss of soft magnetic materials was new technical approach, which could be used to the new nanocrystalline soft magnetic alloy.

Table 1. Magnetic loss P (f) of samples, $\mathrm{WKg}^{-1}$.

\begin{tabular}{|c|c|c|c|c|c|c|c|c|c|c|c|c|}
\hline \multicolumn{13}{|c|}{$\mathrm{P}(\mathrm{f}) / \mathrm{w} \cdot \mathrm{Kg}^{-1}$} \\
\hline \multirow{3}{*}{$\mathrm{Bm} / \mathrm{T}$} & \multicolumn{12}{|c|}{$\mathrm{f} / \mathrm{KHz}$} \\
\hline & \multicolumn{2}{|c|}{600} & \multicolumn{2}{|c|}{500} & \multicolumn{2}{|c|}{400} & \multicolumn{2}{|c|}{300} & \multicolumn{2}{|c|}{200} & \multicolumn{2}{|c|}{100} \\
\hline & $14 \mu \mathrm{m}$ & $26 \mu \mathrm{m}$ & $14 \mu \mathrm{m}$ & $26 \mu \mathrm{m}$ & $14 \mu \mathrm{m}$ & $26 \mu \mathrm{m}$ & $14 \mu \mathrm{m}$ & $26 \mu \mathrm{m}$ & $14 \mu \mathrm{m}$ & $26 \mu \mathrm{m}$ & $14 \mu \mathrm{m}$ & $26 \mu \mathrm{m}$ \\
\hline 0.1 & 246.97 & 354.85 & 171.21 & 256.16 & 115.53 & 175.75 & 64.20 & 112.87 & 31.82 & 54.10 & 10.08 & 16.14 \\
\hline 0.08 & 161.36 & 238.25 & 112.12 & 171.64 & 67.80 & 122.76 & 40.53 & 69.59 & 20.83 & 37.13 & 6.48 & 10.86 \\
\hline 0.06 & 81.82 & 142.72 & 60.23 & 105.78 & 38.26 & 65.86 & 22.73 & 41.23 & 10.98 & 20.62 & 3.56 & 6.32 \\
\hline 0.04 & 35.61 & 63.06 & 26.52 & 45.52 & 18.18 & 30.97 & 9.91 & 18.47 & 4.68 & 9.37 & 1.67 & 2.63 \\
\hline
\end{tabular}

Spectrum of Magnetic Loss. Table 1 given the double logarithmic numerical analysis of $P(f)$ and $f$ data, and the relationship between the $\log P(f)$ and the $\log f$ for the examples were shown in Fig. 1 (under the condition of $\mathrm{B}_{\mathrm{m}}=0.1 \mathrm{~T}, 0.04 \mathrm{~T}$, respectively). it was found that under certain value of $\mathrm{B}_{\mathrm{m}}$ the $\log P(f)$ and the $\log f$ exhibited a good linear relationship, which shown that in the scale-free interval of $f=100 \sim 600 \mathrm{KHz}$, the $\mathrm{P}(\mathrm{f})$ exhibited a typical characteristics of fractal structure, and the $\mathrm{P}$ (f) could be expressed as the formula (1):

$$
\mathrm{P}(\mathrm{f})=\mathrm{P}_{\mathrm{O}} \mathrm{f}^{\mathrm{Df}}
$$

In which, the $\mathrm{D}_{\mathrm{f}}$ was the fractal dimension of the magnetic loss spectrum, the $\mathrm{P}_{\mathrm{o}}$ was a parameter. At different $B_{m}$, the values of $D_{f}$ and $P_{o}$ of both samples were listed in Table 2 . 
In traditional engineering applications, the magnetic loss $\mathrm{P}$ of soft magnetic alloy could be expressed by the empirical formula as the formula (2) [9]:

$$
\mathrm{P}=\mathrm{Pe}+\mathrm{Ph}+\mathrm{Pa}=\mathrm{eBm} 2 \mathrm{f} 2+\eta \mathrm{Bm} 1.6 \mathrm{f}+\mathrm{Pa}
$$

where, the Pe was eddy current loss as equal to $\mathrm{eB}_{\mathrm{m}}{ }^{2} \mathrm{f}^{2}$, the $\mathrm{Ph}$ was hysteresis loss as equal to $\eta \mathrm{B}_{\mathrm{m}}{ }^{1.6} \mathrm{f}$, in which the e and the $\eta$ were the loss coefficient, and the Pa was the remaining loss. However, the formula (2) didn't hold for the highly permeable material at high frequencies, which were approved by a large number of experimental results, and the total loss $P$ couldn't be simplify formulize by the formula (2). The Table 2 shown that, in the present study the fractal dimension $D_{\mathrm{f}}$ were fractional value, indicated that the description $\mathrm{P}(\mathrm{f})$ were fractal structure. The result implied that in the hysteresis loss and the eddy current loss the integer index of 2 and 1 didn't had corresponding physical meaning for the $\mathrm{Ph} \propto \mathrm{f}^{2}$ and the $\mathrm{Ph} \propto \mathrm{f}$, only expressed a unified total loss mechanisms eddy currents, hysteresis, magnetic after effect, which caused by the frequency dependence of the frequency characteristic. The $\mathrm{D}_{\mathrm{f}}$ was more greater, the magnetic material loss became worse. In addition, the formula (1) also had the characteristics of simple form, and the two parameters $P_{o}$ and $D_{f}$ could be determined by the small amount of available experimental data, and could be applied in practical engineering design very easily. Existing research suggested that, the $1 \mathrm{~J} 79$ soft magnetic alloy with high permeability magnetic loss $\mathrm{P}(\mathrm{f})$ had shown a similar fractal structure [10].

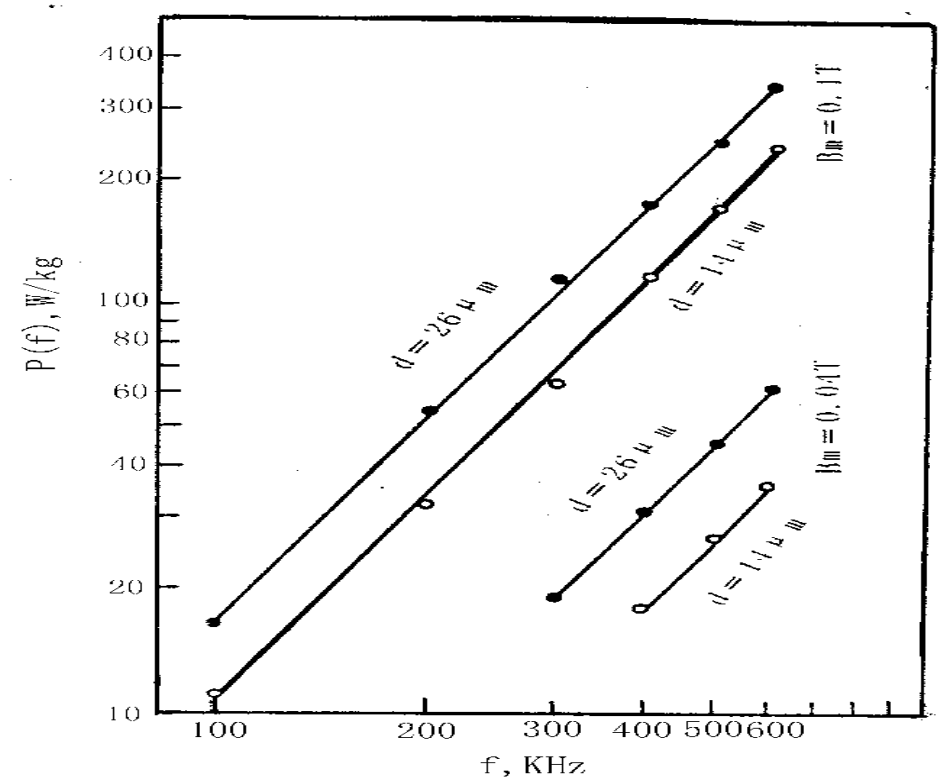

Fig. 1 The relationship between the $\log P(f)$ and the $\log f$.

Table 2. The values of $\mathrm{D}_{\mathrm{f}}$ and $\mathrm{P}_{\mathrm{o}}$ of both samples under different $\mathrm{B}_{\mathrm{m}}$

\begin{tabular}{|c|c|c|c|c|c|c|c|c|}
\hline \multirow{2}{*}{$\mathrm{Bm} / \mathrm{T}$} & \multicolumn{2}{|c|}{0.1} & \multicolumn{2}{c|}{0.08} & \multicolumn{2}{c|}{0.06} & \multicolumn{2}{c|}{0.04} \\
\cline { 2 - 9 } & $14 \mu \mathrm{m}$ & $26 \mu \mathrm{m}$ & $14 \mu \mathrm{m}$ & $26 \mu \mathrm{m}$ & $14 \mu \mathrm{m}$ & $26 \mu \mathrm{m}$ & $14 \mu \mathrm{m}$ & $26 \mu \mathrm{m}$ \\
\hline Df & 1.70 & 1.71 & 1.70 & 1.72 & 1.67 & 1.72 & 1.62 & 1.72 \\
\hline Pox10-3 & 4.19 & 6.36 & 2.77 & 3.90 & 1.78 & 2.38 & 1.03 & 1.01 \\
\hline
\end{tabular}

The Effect of Thickness $\mathbf{d}$ on $\mathbf{D}_{\mathbf{f}}$ and $\mathbf{P}_{\mathbf{o}}$. The $\mathrm{P}_{\mathrm{o}}$ and $\mathrm{D}_{\mathrm{f}}$ values of both samples under different $\mathrm{B}_{\mathrm{m}}$ values were shown in Fig. 2. At different $B_{m}$ values, the $P_{o}$ and $D_{f}$ values of the ribbons with the thickness of $14 \mu \mathrm{m}$ were small than that of conventional alloy thin ribbons with the thickness of 26 $\mu \mathrm{m}$. This suggested that the decrease of $\mathrm{D}_{\mathrm{f}}$ and $\mathrm{P}_{\mathrm{o}}$ were induced by reducing the strip thickness $\mathrm{d}$, so that the magnetic loss of the alloy was lowered, which indicated that the magnetic loss frequency characteristic of ultra-thin ribbons was superior to the conventional alloys. With the increase of the value $B_{m}$, the Po values of both samples were increased too, but the growth rate of $f P_{o}$ in the ultra-thin ribbons were far lower than that of the conventional alloys ribbons. The $\mathrm{D}_{\mathrm{f}}$ values of both samples 
were quite different with variation of $B_{m}$, the $D_{f}$ values of the ultra-thin ribbons increased with the increase of $B_{m}$, but the $D_{f}$ values of the conventional alloys ribbons deceased slightly.

In addition, compared the $\mathrm{D}_{\mathrm{f}}$ and $\mathrm{P}_{\mathrm{o}}$ of the ultra-thin ribbons and the conventional alloys ribbons, it could be found, at lower $B_{m}$, the $P_{o}$ value between the two samples were different, the $P_{o}$ values of the ultra-thin ribbons was much lower than that of the conventional alloys ribbons; at higher $\mathrm{B}_{\mathrm{m}}$, the difference of $D_{f}$ value between the two samples were small, but the $\mathrm{P}_{\mathrm{o}}$ values of the ultra-thin ribbons were little lower than that of the conventional alloys ribbons. This indicated that, at different values of $\mathrm{B}_{\mathrm{m}}$, with a reduced thickness to reduce the magnetic loss had different mechanisms. At lower $\mathrm{B}_{\mathrm{m}}$, the $P(f)$ primarily decreased by reducing the value $D_{f}$, but at higher $B_{m}$, the $P(f)$ were mainly controlled by $\mathrm{P}_{\mathrm{o}}$, and decreased by reducing the value $\mathrm{P}_{\mathrm{o}}$. Therefore, in practice, when working at a lower value of magnetic induction $\mathrm{B}_{\mathrm{m}}$ occasions, compared with the conventional alloys ribbons, the ultra-thin ribbons were selectable to use at high frequency; in the case of higher $\mathrm{B}_{\mathrm{m}}$, the ultra-thin ribbons could work at a more higher value of $\mathrm{B}_{\mathrm{m}}$. It was undoubted that the ultra-thin ribbons were very useful for the miniaturization of small high-frequency soft magnetic device.

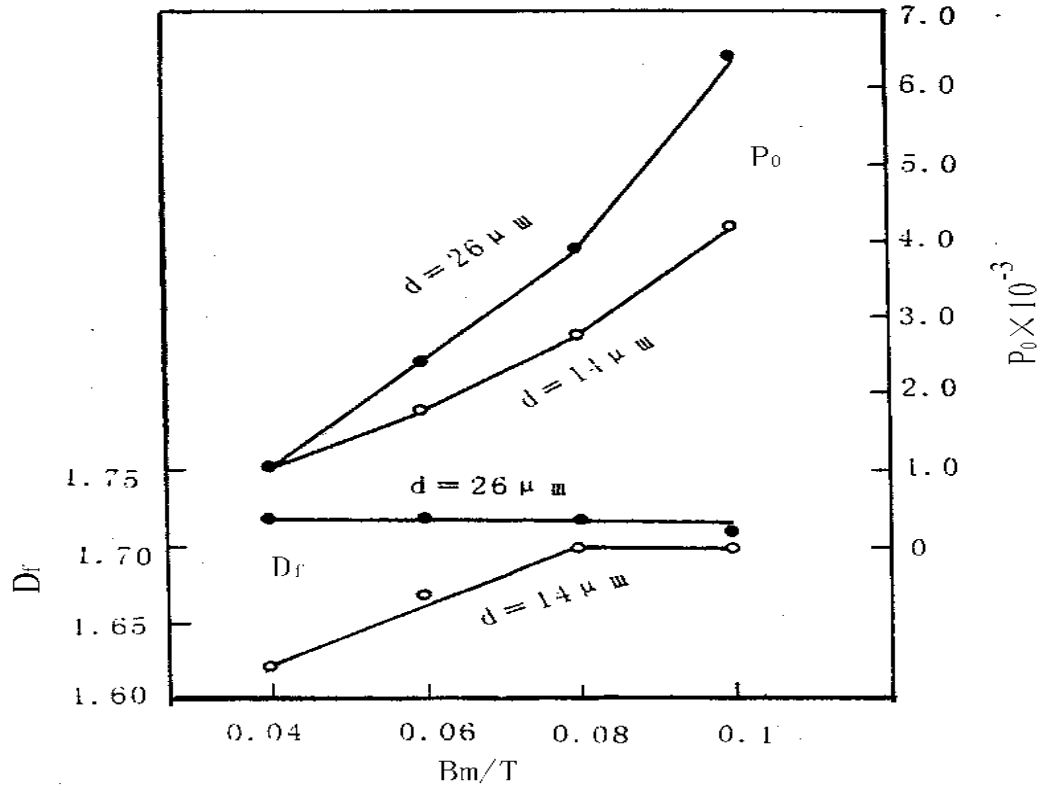

Fig. 2 Relations between $\mathrm{D}_{\mathrm{f}}, \mathrm{P}_{0}$ and $\mathrm{d}, \mathrm{B}_{\mathrm{m}}$.

\section{Summary}

The magnetic loss nanocrystalline soft magnetic ribbons could be significantly reduced with reducing the thickness of the nanocrystalline soft magnetic ribbons. The magnetic loss of the ribbons with the thickness of $14 \mu \mathrm{m}$ was reduced to $70 \%$ of that of the ribbons with the thickness of $26 \mu \mathrm{m}$.

The magnetic loss $\mathrm{P}$ (f) of nanocrystalline soft magnetic ribbons had a fractal structure, and could be formulized as: $\mathrm{P}(\mathrm{f})=\mathrm{P}_{\mathrm{o}} \mathrm{f}^{\mathrm{Df}}$.

The $P_{o}$ and $D_{f}$ values were decreased with reducing the thickness of the nanocrystalline soft magnetic ribbons. Under different ribbons thickness, the Po and Df of nanocrystalline soft magnetic ribbons shown a different disciplinarian under changes of work magnetic induction Bm values.

\section{Acknowledgments}

This work was supported by the National Natural Science Foundation of China (Grant no. 51401184), the Basic Research Projects of National Defense of China (Grant no. JCKY2016208C004), and the Postdoctoral Science Foundation of Ningbo Branch of China Academy of Ordnance Science (NBPJ2013-6). 


\section{References}

[1] Q. Z. Zhi, B. S. Dong, W. Z. Chen, K. Y. He, Elevated temperature initial permeability study of Fe73. 5Cu1Nb3Si13. 5B9 alloy, Mater. Sci. Eng. A 448 (2007) 249-252.

[2] Y. Z. Zhang, Microstructure and temperature dependence of susceptibility of different annealed nanocrystalline Fe73. 1Cu1. 2Nb Si12. 5B10 alloy, J. Funct. Mater. Dev. 1-3 (1997) 88-93.

[3] K. Y. He, Magnetothermal analysis of Fe72. 7Cu1Nb2V1. 8Si13. 5B9 alloy, Acta metallurg. Sin. 33 (1997) 12: 356-359.

[4] J. F. Loffler, J. P. Meier, B. Doudin, J. P. Ansermet, W. Werner, Random and exchange anisotropy in consolidated nanostructured $\mathrm{Fe}$ and $\mathrm{Ni}$ : role of grain size and trace oxides on the magnetic properties, Phys. Rev. B 57 (1998) 2915-2924.

[5] H. Ucar, J. Ipus, V. Franco, M. E. Mchenry, D. E. Laughlin, Overview of Amorphous and Nanocrystalline Magnetocaloric Materials Operating Near Room Temperature, J. Min. Metal. Mater. Soc. 64 (2012) 782.

[6] Y. Yoshizawa, S. Oguma, K. Yamauchi, New Fe-based soft magnetic alloys composed of ultrafine grain structure, J. Appl. Phy. 64 (1988)6044-6046.

[7] X. D. Fan, H. Men, A. B. Ma, B. L. Shen, Soft magnetic properties in Fe84-xB10C6Cux nanocrystalline alloys, J. Magn. Magn. Mater. 326 (2013) 22-27.

[8] F. G. Chen, Y. G. Wang, X. F. Miao, H. Hong, K. Bi, Nanocrystalline Fe83P16Cu1 soft magnetic alloy produced by crystallization of its amorphous precursor, J. Alloy. Comp. 549 (2013) 26-29.

[9] D. F. Wan, X. L. Ma. Magnetic Physics. Chengdou, University of Electronic Science and Technology Press, 1994, pp. 406.

[10]M. Ohta, Y. Yoshizawa, High Bs nanocrystalline Fe84-x-yCuxNbySi4B12 alloys (x=0. 0-1. 4, $\mathrm{y}=0-2$. 5), J. Magn. Magn. Mater. 321 (2009) 2220-2224. 